\title{
Determination of Free DNA (cfDNA) by RT-qPCR in Individuals in Sperm Alterations
}

\author{
Modou Mamoune Mbaye ${ }^{1^{\star}}$, Hasnae Zekhnini ${ }^{2}$, Bouchra El Khalfi ${ }^{1}$, \\ Noureddine Louanjli ${ }^{3}$, Mustafa Zakaria ${ }^{4}$, Fatiha Elmellouli ${ }^{2}$ and Abdelaziz Soukri ${ }^{1}$ \\ ${ }^{1}$ Physiopathology Molecular Genetics and Biotechnologies Laboratory, Faculty of Sciences Ain \\ Chock, Center of Health and Biotechnology, Hassan II University, Casablanca, Morocco. \\ ${ }^{2}$ Regional Laboratory of Analysis and Research Casablanca, National Office for Food Safety \\ "ONSSA", Morocco. \\ ${ }^{3}$ In Vitro Fertilization Center IRIFIV, IRIS Clinic, Casablanca, Morocco. \\ ${ }^{4}$ IRIFIV Fertility Center, IVF laboratory, Casablanca, Morocco.
}

\section{Authors' contributions}

This work was carried out in collaboration among all authors. All authors read and approved the final manuscript.

Article Information

\author{
DOI: 10.9734/ARRB/2021/v36i530369 \\ Editor(s): \\ (1) Paola Angelini, University of Perugia, Italy. \\ Reviewers: \\ (1) MD. Selim Morshed, University of Dhaka, Bangladesh. \\ (2) Guilherme Rizzoto, University of Calgary. Canada. \\ (3) Seda Karabulut, Istanbul Medipol University, Turkey. \\ Complete Peer review History: http://www.sdiarticle4.com/review-history/59391
}

Original Research Article

Received 05 June 2020

Accepted 10 August 2020

Published 04 May 2021

\section{ABSTRACT}

Previous studies have suggested that the presence of circulating nucleic acids (cell-free DNA) in seminal plasma may indicate disease states. However, the potential association between cell-free DNA (cfDNA) levels in seminal plasma and sperm fertility parameters has not yet been definitively determined.

In this study, we will compare seminal free DNA levels between normozoospermic samples and those from different pathologies related to characteristic parameters of sperm quality (asthenozoospermia, azoospermia, teratozoospermia, oligozoospermia and a few samples with a high fragmentation index) in order to detect a potential association between free DNA levels in seminal plasma and these different pathologies of male fertility.

The recovery of free DNA from our different samples was done with the MACHEREY-NAGEL NucleoSpin $®$ kit. This kit allows isolation of DNA from cell-free biological fluids using rapid silica 
column procedures. The quantification of free DNA in our samples was performed by quantitative PCR (RT-qPCR).

Our results showed a significant difference in the level of free seminal DNA between normozoospermic samples and oligozoosperimic, teratozoosperimic, azoosperimic samples and those with a high DNA fragmentation index. On the other hand, no significant difference in the level of seminal free DNA was noted between normozoospermic and asthenozoospermic samples.

These results suggest that seminal free DNA may be an important biomarker in the assessment of human sperm fertility.

Keywords: Cell-free DNA; oligozoospermic; teratozoospermic; azoospermic and normozoospermic.

\section{INTRODUCTION}

Circulating nucleic acids (cell-free DNA) constitute a very important source of noninvasive biomarkers which are very useful in current practice for the detection and monitoring of various pathologies [1]. Circulating nucleic acids including free DNA result from the release of dying cells [2]. According to the VLASSOV et al team, living cells can also release them [3].

In human pathology, they are the diagnostic and I or prognostic tools of choice, owing to the fact that they can be easily dosed in different biological fluids, in particular amniotic fluid [4], blood plasma [5], and cerebrospinal fluid [4,6], saliva [7], blood [8] and urine [9].

Since then, in recent years, they have found a very growing interest in several fields and potential clinical applications such as cancer detection and prognosis, prenatal diagnosis, forensic investigation and human fertility with the sole aim of being able to improve the management of infertile couples or even the poor results of in vitro fertilization [10].

Thus, in medically assisted procreation (MAP), circulating nucleic acids have proven their effectiveness in evaluating the quality of the follicular microenvironment [11], in identifying certain pathologies of the ovarian reserve [12], in predicting embryonic development in vitro [13] and to detect potential abnormalities in spermatogenesis [14]. Moreover, it is in this sense that several studies have shown a significant difference in the rate of free seminal nucleic acids between azoospermic and normozoospermic samples $[2,10,12]$.

In this present study, we will compare the levels of free nucleic acids between a few different pathologies of sperm quality (oligozoosperimic, teratozoosperimic, azoosperimic and those with a high DNA fragmentation index) and the normozoospermic sample in order to detect them. a possible association between each abnormality and the level of cell-free DNA.

\section{MATERIALS AND METHODS}

\subsection{Collecting Samples}

The collection of our samples was carried out at the Laboratory of Medical Analysis and Reproductive Biology, "Labomac", Casablanca, Morocco. We had to establish a group of 18 samples divided into different subgroups according to the specifications of the WHO (2010): 3 samples from men diagnosed as normozoospermic (progressive motility $\geq 32 \%$ ), 3 samples from men diagnosed as Asthenozoospermic (progressive motility $<32 \%$ ), 3 samples from men diagnosed as Azoospermic (absence of sperm in the ejaculate), 3 samples from men diagnosed teratozoospermic (normal sperm $\leq 4 \%)$, 3 samples from men diagnosed oligozoospermic (sperm count $<15$ million $/ \mathrm{mL}$ ), 3 samples from men diagnosed with high DNA fragmentation index (TUNEL Assay with a result $>4 \%)$.

\subsection{Preparation of Our Samples}

To confirm the presence and quantify free seminal DNA (CfDNA) in our various samples. Our seminal plasmas were obtained by low speed centrifugation to avoid cell lyses $(500 \times \mathrm{g}$ for $10 \mathrm{~min}$ and the seminal plasma was then centrifuged again at $10,000 \times \mathrm{g}$ for $5 \mathrm{~min}$ ). Seminal plasma obtained by high-speed centrifugation was subjected directly to the isolation of seminal free DNA (CfDNA).

\subsection{Recovery of Free DNA}

This study was carried out at the molecular biology unit at the regional analysis and research laboratory of the National Office of Sanitary Safety of Food Products "ONSSA", Morocco. 
The recovery of free DNA from our different samples was done with the MACHEREY-NAGEL NucleoSpin $®$ kit. This kit allows the isolation of DNA from biological fluids using rapid silica column procedures. No extraction of phenol chloroform was necessary. DNA specifically binds to the MACHEREY-NAGEL NucleoSpin ${ }^{\circledR}$ silica membrane as contaminants pass through. PCR inhibitors such as cations and divalent proteins are completely removed in three efficient wash steps leaving pure DNA to elute in water (RNase-Free $\mathrm{H} 2 \mathrm{O}$ ) supplied with the kit.

The test sample size was $200 \mu$ for each sample giving a final elution volume of $50 \mu \mathrm{l}$. The extractions were made in a dedicated room, at room temperature, under a biological safety cabinet (BSC) and after careful cleaning of the bench to avoid contamination as much as possible.

\subsection{Measuring the Distribution of Free DNA Quantities}

For the quantification of free DNA, real-time PCR was performed as described above [2] with an Applied Biosystems 7500 Fast Real-Time PCR system using SYBR GREEN fluorescence detection of amplified products. For our q RT$\mathrm{PCR}$, we used the human growth differentiation factor (hGDF) gene, a regulator of cell growth and differentiation in embryonic and adult tissues. The two primer pairs were as follows: forward 5'-CGCAGAGGTCAGGAAACTGTC-3 ', reverse 5'-GGCAGGTACACATGACGGTCT-3. It was chosen for its cellular and ubiquitous specificities.

Duplicate measurements were carried out per sample and a four-step temperature protocol was applied as follows: $95^{\circ} \mathrm{C}$ for $10 \mathrm{~min}$ (initial denaturation); 35 cycles of $25 \mathrm{~s}$ at $95^{\circ} \mathrm{C}$ (denaturation); $30 \mathrm{~s}$ at $60^{\circ} \mathrm{C}$ (annealing), $30 \mathrm{~s}$ at $72^{\circ} \mathrm{C}$ (elongation) and $8 \mathrm{~s}$ at $84^{\circ} \mathrm{C}$ (fluorescence measurement). A melting curve was generated at the end of each cycle to ensure product consistency. The calibration curve was constructed using CfDNA concentrated in serial dilutions.

\subsection{Statistical Analysis}

The data obtained in our experiment were subjected to a statistical study. The comparison of our results between the levels of free
DNA found in our different pathological samples (oligozoospermic, teratozoospermic, azoospermic and those with a high index of DNA fragmentation) and the normozoospermic sample was done by Student's t-test. All the graphs and histograms represented in this article were made with the software: GraphPadPrism7.

\section{RESULTS}

Each seminal plasma sample was measured in duplicate. From these two values, we had to calculate the average concentration.

The measured values were in $\mu \mathrm{g} / \mathrm{ml}$.

The lowest value was $0.08 \mu \mathrm{g} / \mathrm{ml}$ while the highest was $1.47 \mu \mathrm{g} / \mathrm{ml}$.

The «control» normozoospermic group had seminal free DNA concentrations of $0.39 \pm 0.42$ $\mu \mathrm{g} / \mathrm{ml}$ with a minimum at $0.08 \mu \mathrm{g} / \mathrm{ml}$ and a maximum at $0.10 \mu \mathrm{g} / \mathrm{ml}$.

Analysis of each abnormality compared to normozoospermic samples showed:

Comparison of the rate of free seminal DNA (CfDNA) of normozoospermic samples (0.09 \pm $0.01 \mu \mathrm{g} / \mathrm{ml}$ ) and that with a high index of DNA fragmentation $(1.10 \pm 0.44 \mu \mathrm{g} / \mathrm{ml})$ showed a significant increase $(p=0.052)$ in the latter (Fig. 1A).

The comparison of the rate of free seminal DNA (CfDNA) between normozoospermic samples $(0.09 \pm 0.01 \mu \mathrm{g} / \mathrm{ml})$ and that of oligozoospermic samples $(1.26 \pm 0.22 \mu \mathrm{g} / \mathrm{ml})$ showed a significant increase $(p=0.051)$ in the latter (Fig. 1B)

The comparison of the rate of free seminal DNA (CfDNA) of normozoospermic samples (0.09 \pm $0.01 \mu \mathrm{g} / \mathrm{ml}$ ) and that of teratozoospermic samples $(1.30 \pm 0.22 \mu \mathrm{g} / \mathrm{ml})$ showed a significant increase $(p=0.01)$ in the latter (Fig. 1C).

Comparison of the free DNA level of normozoospermic samples $(0.09 \pm 0.01 \mu \mathrm{g} / \mathrm{ml})$ and that of azoospermic samples $(1.25 \pm 0.09 \mu \mathrm{g}$ $/ \mathrm{ml})$ showed a significant increase $(\mathrm{p}=0.003)$ in the latter (Fig. 1D).

Comparison of the seminal free DNA (CfDNA) level of asthenozoospermic patients $(0.85 \pm 0.01$ $\mu \mathrm{g} / \mathrm{ml}$ ) and that of normozoospermic samples $(0.09 \pm 0.01 \mu \mathrm{g} / \mathrm{ml})$ showed no significant difference. 

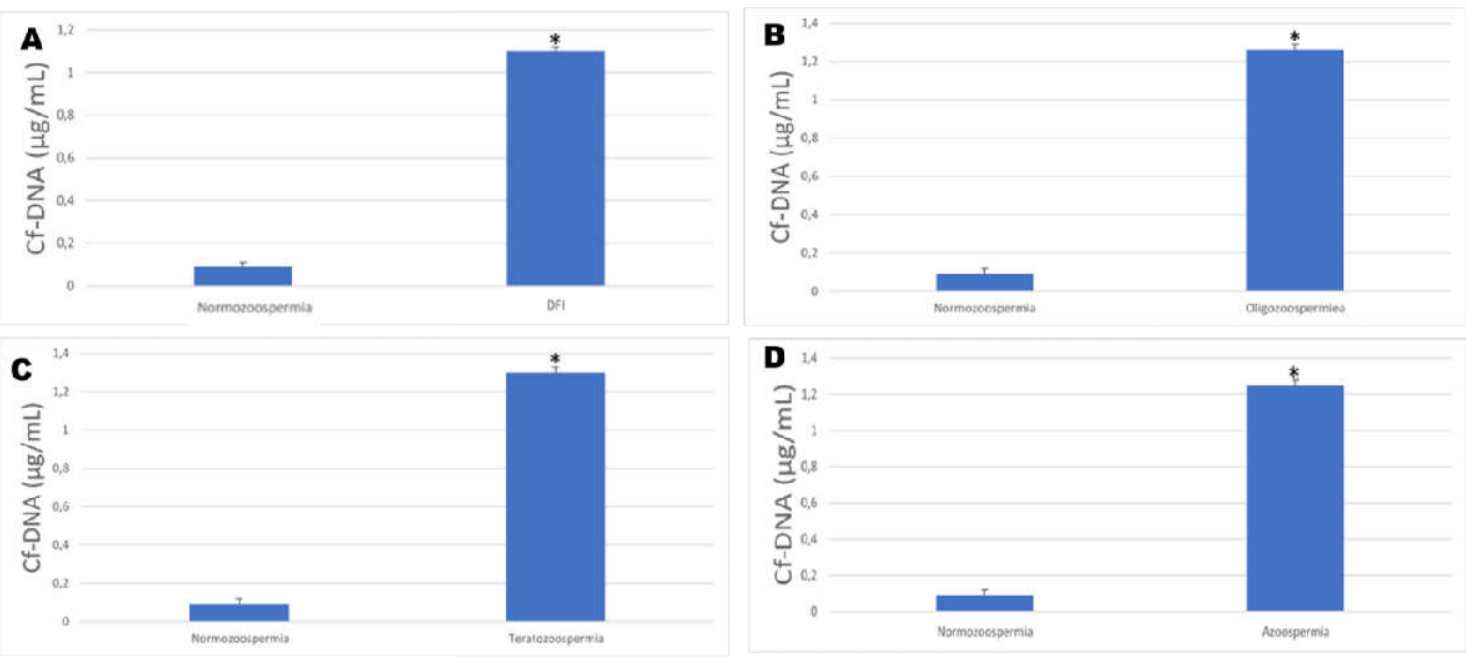

Fig. 1. Comparison of seminal free DNA (CfDNA) levels between samples of each pathology (high DNA fragmentation index (DFI) $(n=3)(A)$, oligozoospermic $(n=3)(B)$, oligozoospermic $(n=3)$, teratozoospermic $(n=3)(C)$ and azoospermic $(n=3)(D))$ and that of normozoospermic samples $(n=3))$ s. Data are expressed as mean \pm standard deviation

\section{DISCUSSION}

The aim of this study was to compare the seminal free DNA (CfDNA) levels of some pathologies of sperm quality (asthenozoospermia, oligozoospermia, teratozoospermia, azoospermia and those with a high DNA fragmentation index) and the samples. normozoospermic in order to detect a possible potential between these levels of free seminal DNA and these various pathologies.

This study also confirmed the presence of free DNA in human sperm plasma.

The characteristics of our standard curve, namely: the correlation coefficient (R2) (0.995), the slope (-3.285) and the efficiency (109.335) show that our QRT-PCR worked perfectly and allowed satisfactory amplifications.

Analysis of our results showed that the comparison between the seminal free DNA (CfDNA) levels of normozoospermic samples and some abnormalities such as those with a high DNA fragmentation index $(p=0.052)$ (Fig. $1 A)$, the oligozoospermic samples $(p=0.051)$ (Fig. 1B), the teratozoospermic samples $(p=$ 0.01 ) (Fig. 1C) and the azoospermic samples ( $p$ $=0.003$ ) (Fig. 1D) showed a significant difference. In contrast, comparison of free seminal DNA levels between asthenozoospermic and normozoospermic samples showed no significant difference. Thus, we can say that the results for this sample cohort seem encouraging.

Our results are in line with the results of Pierre $\mathrm{Di}$ Pizio who found significant differences in the level of seminal CfDNA in azoospermic ( $p=$ $0.03)$, teratozoospermic $(p=0.008)$ patients and an absence of significant difference between the levels of seminal CfDNA in patients versus matched controls. Unlike us, he found an absence of significant difference between circulating seminal DNA concentrations in oligozoospermic patients and controls [15].

Our results also on the significant increase in the level of CfDNA in the azoospermic patients ( $P=$ 0.003 ) and the controls are in perfect with those of $\mathrm{Li}$ et al, who found a significant increase of $(P<0.05)[16]$.

According to the team of Gonzales et al, the presence of free seminal DNA in human sperm is due to several processes such as apoptosis, necrosis and / or netosis which lead to DNA release. free in the extracellular environment [17]. It is in this same perspective that the team of Brinkmann et al, showed that the presence of free seminal DNA in oligozoospermic patients would result from a deficient spermiogenesis. That is, when sperm maturation is poor, cellular checkpoints come into play and cause these defective elements to go into apoptosis [18]. However, the presence of free seminal DNA in patients with a high DNA fragmentation index is 
not well documented. Nevertheless, it can be thought that it is due either to the apoptosis of germ cells during spermatogenesis in mammalian testes [18], or to the result of secretions by cells of the glandular organs, namely the secretions of seminal vesicles, prostate and bulburethral glands, which make up about $90 \%$ of semen volume. According to the team of Dimopoulou et al, the presence of high seminal free DNA in teratozoospermic patients results from deficient spermiogenesis [19].

Certain pathological conditions, such as certain inflammations, cancers, trauma, etc., which cannot be detected by current WHO guidelines, may contribute to high concentrations of free DNA [20].

\section{CONCLUSION}

Significant increases in seminal free DNA (CfDNA) levels in teratospermia, oligozoospermia, azoospermia, and high fragmentation index compared to controls show that seminal CfDNAs may be important biomarkers in the management of infertility of these abnormalities. In contrast, in asthenozoospermic patients no significant difference was noted.

\section{CONSENT}

Informed consent was obtained from all patients included before using their sperm in this study. Samples were then collected after 3 to 4 days of abstinence in sterile, labelled containers [13].

\section{ETHICAL APPROVAL}

As per international standard or university standard written ethical approval has been collected and preserved by the author(s).

\section{COMPETING INTERESTS}

Authors have declared that no competing interests exist.

\section{REFERENCES}

1. Jing $\mathrm{R}$, Cui RM, Wang $\mathrm{H}$ and Ju S. Cellfree DNA: characteristics, detection and its applications in myocardial infarction. Current Pharmaceutical Design. 2013; 19(28):5135-5145.
2. Li HG, Huang SY, Zhou H, Liao AH, Xiong CL. Quick recovery and characterization of cell-free DNA in seminal plasma of normozoospermia and azoospermia: implications for non-invasive genetic utilities. Asian Journal of Andrology. 2009; 11(6):703.

3. Vlassov VV, Laktionov PP, Rykova EY. Extracellular nucleic acids. Bioessays. 2007;29(7):654-667.

4. Lapaire O, Bianchi DW, Peter I, O'Brien B, Stroh H, Cowan JM, Johnson KL. Cell-free fetal DNA in amniotic fluid: Unique fragmentation signatures in euploid and aneuploid fetuses. Clinical Chemistry. 2007;53(3):405-411.

5. Swarup V, Rajeswari MR. Circulating (cell-free) nucleic acids-a promising, non-invasive tool for early detection of several human diseases. FEBS Letters. 2007;581(5):795-799.

6. Wong LC, Perng $\mathrm{CL}$, Hsu $\mathrm{CH}$, Bai RK, Schelley S, Vladutiu GD, Enns GM. Compensatory amplification of mtDNA in a patient with a novel deletion/duplication and high mutant load. Journal of Medical Genetics. 2003;40(1)1: e125-e125.

7. Watson JD, CrickFH. A structure for deoxyribose nucleic acid. Nature. 1953; 171(4356):737-738.

8. Zubakov D, Hanekamp E, Kokshoorn M, van IJcken W, Kayser M. Stable RNA markers for identification of blood and saliva stains revealed from whole genome expression analysis of time-wise degraded samples. International Journal of Legal Medicine. 2008;122(2):135-142.

9. Schmidt B, Carstensen T, Engel E, Jandrig B, Witt C, Fleischhacker M. Detection of cell-free nucleic acids in bronchial lavage fluid supernatants from patients with lung cancer. European Journal of Cancer. 2004; 4093:452-460.

10. Hoque $\mathrm{MO}$, Begum S, Topaloglu $\mathrm{O}$, Chatterjee A, Rosenbaum E, Van Criekinge W, Sidransky D. Quantitation of promoter methylation of multiple genes in urine DNA and bladder cancer detection. Journal of the National Cancer Institute. 2006;98(14):996-1004.

11. Chou JS, Jacobson JD, Patton WC, King A, Chan PJ. Modified isocratic capillary electrophoresis detection of cell-free DNA in semen. Journal of Assisted Reproduction and Genetics. 2004;21(11): 397-400. 
12. Czamanski-Cohen J, Sarid O, Cwikel J, Lunenfeld E, Douvdevani A, Levita E, HarVardi I. Increased plasma cell-free DNA is associated with low pregnancy rates among women undergoing IVF-embryo transfer. Reproductive Biomedicine Online. 2013;26(1):36-41.

13. Zhang $\mathrm{R}$, Shao $\mathrm{F}$, Wu X, Ying, K. Value of quantitative analysis of circulating cell free DNA as a screening tool for lung cancer: $A$ meta-analysis. Lung Cancer. 2010;69(2): 225-231.

14. Mbaye MM, El Khalfi B, Addoum B, Mar PD, Saadani B, Louanjli N, Soukri A. The effect of supplementation with some essential oils on the mobility and the vitality of human sperm. The Scientific World Journal. 2019;2019.

15. Arribas R, Capella G, Tórtola S, Masramon L, Grizzle WE, Perucho M et Peinado MA. Évaluation des dommages génomiques dans le cancer colorectal par empreinte ADN: Applications pronostiques. Journal D'oncologie Clinique. 1997;15(10):32303240.
16. Pierre Di Pizio. Free nucleic acid assay and male infertility: perspectives in medically assisted reproduction. Human Medicine and Pathology; 2016. <dumas01369595>

17. Gonzales GF. Function of seminal vesicles and their role on male fertility. Asian Journal of Andrology. 2001;3(4):251258.

18. Brinkmann V, Reichard U, Goosmann C, Fauler B, Uhlemann Y, Weiss DS, Zychlinsky A. Neutrophil extracellular traps kill bacteria. Science. 2004;303(5663): 1532-1535.

19. Dimopoulou M, Anifandis G, Messini Cl, Dafopoulos K, Kouris S, Sotiriou S, Messinis IE. Follicular fluid oocyte/ cumulus-free DNA concentrations as a potential biomolecular marker of embryo quality and IVF outcome. BioMed Research International; 2014.

20. Gahan $P$, Anker P, Stroun M. Metabolic DNA as the origin of spontaneously released DNA?. Annals of the New-York Academy of Sciences. 2008;1137(1):7.

(C) 2021 Mbaye et al.; This is an Open Access article distributed under the terms of the Creative Commons Attribution License (http://creativecommons.org/licenses/by/4.0), which permits unrestricted use, distribution, and reproduction in any medium, provided the original work is properly cited. 